\title{
Comparison of Stress in Conventional Cast and Resin-Luted Implant Frameworks. A Finite Element Analysis Study
}

\author{
Daniela JE' and Juan del VL ${ }^{2 *}$ \\ ${ }^{1}$ Resident Dentist, Ecuador \\ ${ }^{2}$ Professor Central University of Ecuador
}

ISSN: 2637-7764

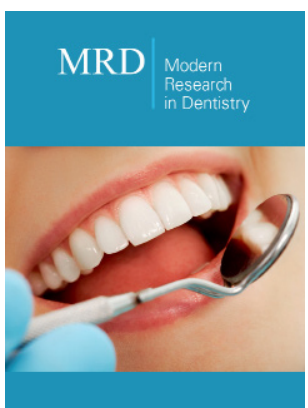

\begin{abstract}
Aim: Many articles have been published on complete-arch implant prostheses. The conventional option is the cast framework technique (CF) which is screw or cement retained; however, there is little information on Retrievable Cement-retained (RCR) implant-supported prosthesis. Therefore it has not been possible to establish which prosthesis performs better biomechanically. The purpose of this finite element analysis (FEA) was to evaluate the biomechanical differences between cast and retrievable Cement-retained (RCR) implant-supported prosthesis in a complete-arch implant prosthesis.
\end{abstract}

Material and Methods: Two 3-dimensional FEA models of a complete-arch implant prosthesis framework one CF and one RCR over five inter foraminal implants were developed and two models were covered with acrylic. A vertical load of $613 \mathrm{~N}$ was applied to all teeth. The maximum von Mises equivalent stresses (SEQV), displacement, and safety factors were set as output variables.

Professor Central University of Ecuador

Results: The RCR prosthesis demonstrated 4,08\% less SEQV than the CF, the SEQV was higher between the abutment and implant in the CF conversely in RCR there is not a specific position because the cement acts as a damper. Displacement pattern was $33.82 \%$ less in the RCR. The safety factor of the RCR was 1.57 and 1.67 for the $\mathrm{CF}$

Published: 湝 May 06, 2019

Volume 4 - Issue 1

How to cite this article: Daniela J, Juan del V. Comparison of Stress in Conventional Castand Resin-Luted Implant Frameworks. A Finite Element Analysis Study. Mod Res Dent. 4(1). MRD.000577.2019.

DOI: 10.31031/MRD.2019.04.000577

Copyright@ Juan del VL, This article is distributed under the terms of the Creative Commons Attribution 4.0 International License, which permits unrestricted use and redistribution provided that the original author and source are credited.

Conclusion: The RCR showed a better distribution of stress in comparison to the CF.

Keywords: Failure analysis; Full edentulism; Prosthetic procedure

Abbreviations: CFT: Cast Framework Technique; RCR: Retrievable Cement-Retained; SEQV: The maximum von Mises equivalent stresses; FEA: Finite Element Analysis

\section{Introduction}

Many articles have been published on complete-arch implant prosthesis $[1,2]$. Frameworks have been conventionally performed by a casting protocol in the laboratory through cast-on abutments [3]. Cast prosthesis could be cement or screw retained. Nowadays these prostheses can be made using CAD-CAM4; [4] however, an alternative way of performing these prostheses is by RCR with access channel $[5,6]$. This provides passive adjustment and retrievability. Passive prosthesis fit is one of the most important factors for correct implant and prostheses performance [7]. Misfit is the main problem, the product of several factors that occur during the manufacture of the cast prosthesis, such as distortion of the dental impression, distortion of the master cast, distortion during the casting [8]. For example, these can result in bone loss, loosening of the screw, and fractures [9]. In comparison, the RCR appears to have a better passive fit because the superstructure is cemented to titanium abutments, which have perfect fit, and the cement absorbs and distributes the occlusal force more efficiently [10-13]. Further maintain the retrievability due to access channel. Some studies have performed in vitro tests of RCR, single-unit implant crown $[14,15]$, three unit [10], and complete-arch framework [6]. These demonstrated that RCR produce a better biomechanical performance as they present a better passive fit and stress distribution; thus, the objective of the present study is to deepen the knowledge of the RCR with access channel through a finite element study. 


\section{Hypothesis}

The RCR will have a better biomechanical performance.

\section{Material and Methods}

A 3D FEA model of a hybrid (metal-acrylic) prosthesis on five interforaminal implants was created, two types of prosthesis were analyzed, one a cast framework (Figure 1) and the other a retrievable Cement-retained (Figure 2). The computer simulation used software (Solidworks 2012 SP0.0 premium package; SolidWorks Corp). The maximum von Mises equivalent stresses (SEQV) measured in Mpa, displacement pattern (measured in $\mathrm{mm}$ ), and the safety factor between these two models were evaluated. A $209 \mathrm{~mm}$ mandibular body was modeled, with five implants of Table 1: Materials of the different parts of the hybrid prosthesis with their mechanical properties

\begin{tabular}{|c|c|c|}
\hline Material & Modulo Elastico (MPa) & Modulo Cortante (MPa) \\
\hline Hueso mandibula & 15000 & 5800 \\
\hline Titanio & 110000 & 40740 \\
\hline Acrilico & 3800 & 1428 \\
\hline Coping (cr co) barra & 218000 & 81950 \\
\hline Cemento & 22400 & 0,33 \\
\hline
\end{tabular}

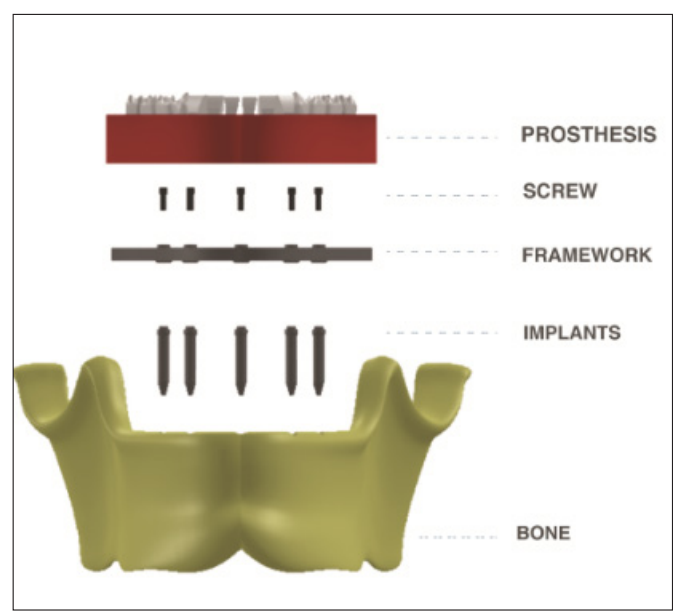

Figure 1: 3D modeling cast framework.
$4.1 \times 11 \mathrm{~mm}$ separated by $2 \mathrm{~mm}$, and a hybrid prosthesis $38 \mathrm{~mm}$ long $\times 14 \mathrm{~mm}$ high, cantilever $15 \mathrm{~mm}$. (Figure 3 ) In the CF a directly screwed bar was made while in the RCR a bar was cemented to five titanite abutments with access channel. All materials were considered homogeneous, isotropic, and linearly elastic. The modulus of elasticity and the Poisson ratio were introduced into the software using the data shown in Table 1. All components were considered to have bonded contacts, which means that they were displaced as a single unit and did not penetrate each other. In this study, polygonal solid elements were used to form a thin, solid mesh with 62,748 elements and 10,0145 nodes. A force of $613 \mathrm{~N}$ distributed throughout the hybrid prosthesis was applied,15 and von Mises stress, displacement, and safety factor were quantified.

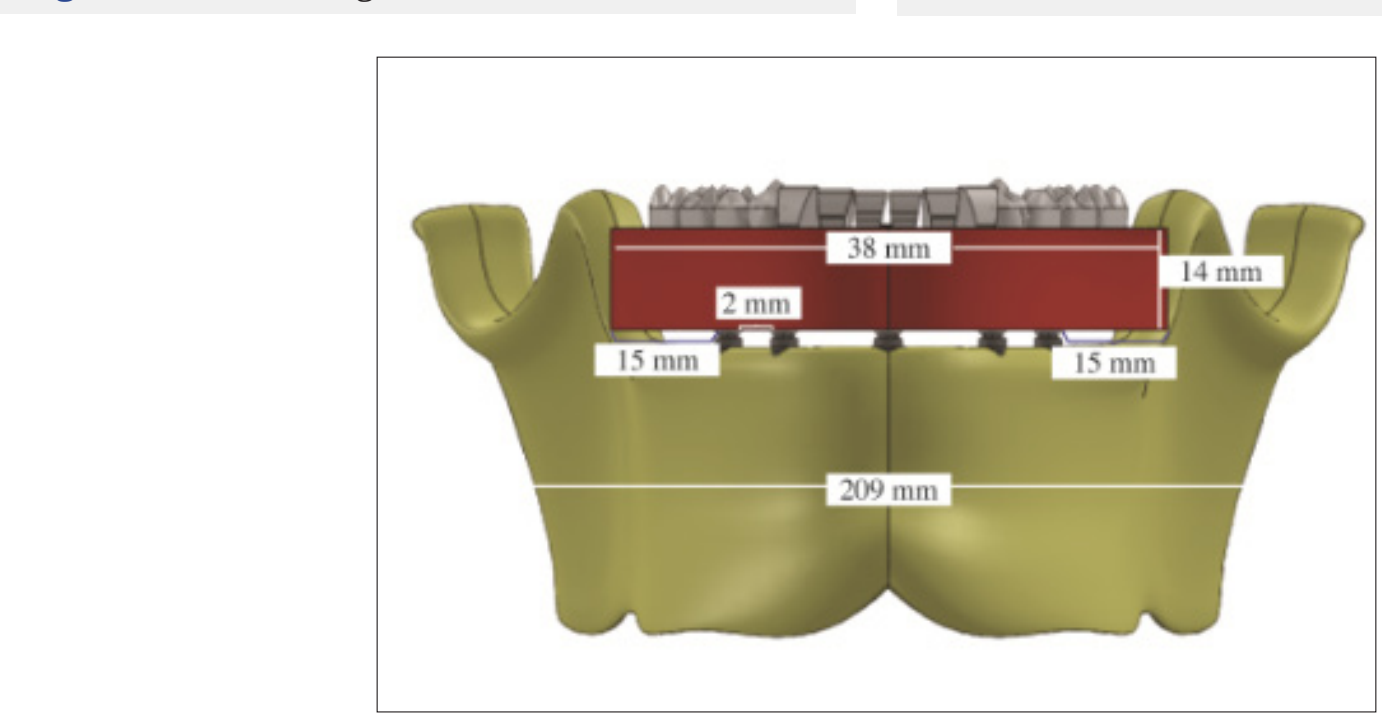

Figure 3: 3D model 


\section{Results}

The SEQV of the RCR was 4,08 less than the CF. This is attributed to the passive fit and cement, which has a function of damper; that is to say the cement helps the prosthesis to distribute stress, avoiding concentration in specific points, unlike in the cast prostheses where stress is concentrated in the implant abutment interface (Figure
4). The displacement pattern in the cast prosthesis was $33,82 \%$ greater than in retrievable Cement-retained but nevertheless was in the same point (Figure 5). The safety factor was approximately 1.57 retrievable Cement-retained and 1.67 for the cast. The point with less safety factor was the hole of the implants in two models (Figure 6). Considering that the minimum safety factor is 1.23 , both designs are considered to be reliable.

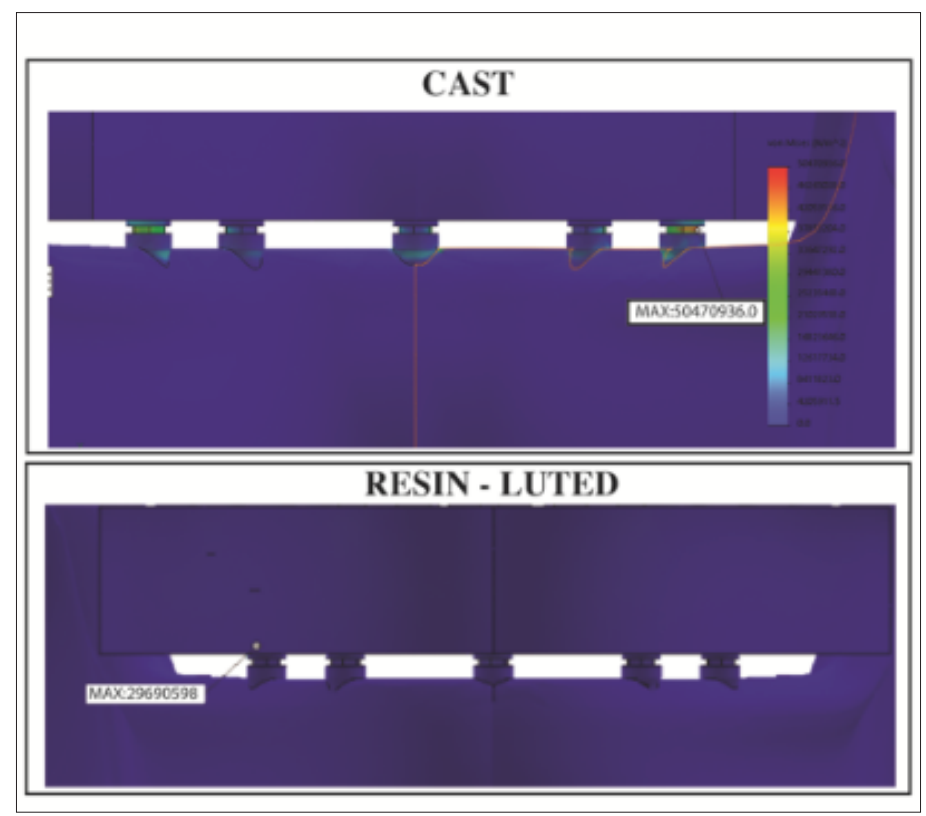

Figure 4: Comparative stress distribution between two models.

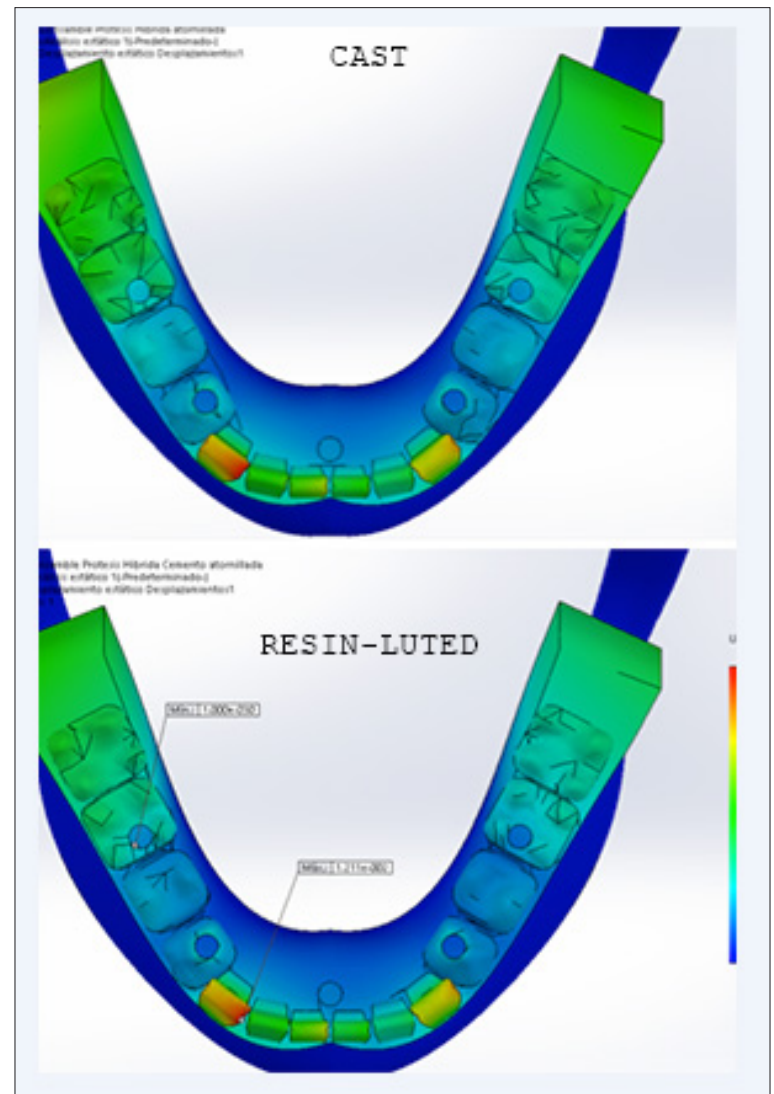

Figure 5: Comparative displacement pattern between two models 


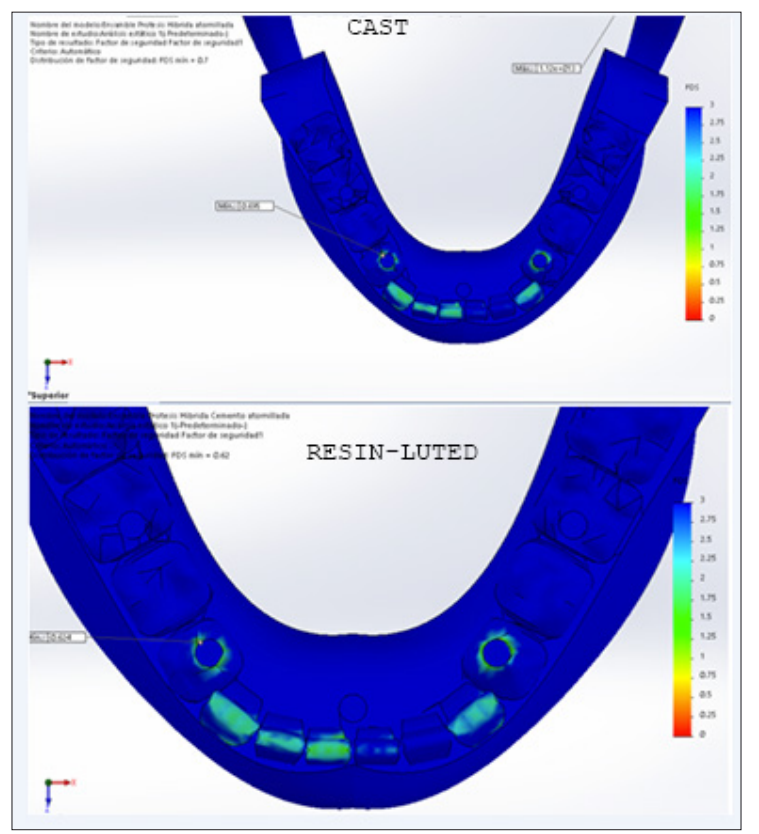

Figure 6: The point with less safety factor was the hole of the implants in two models.

\section{Discussion}

In the present study, a comparison was made between cast and retrievable Cement-retained through FEA. Retrievable Cementretained demonstrated a better distribution of stress, which is in agreement with Clelland NL [6] who used strain gauges to compare two types of prosthesis, concluding that the retrievable Cementretained transfer less stress and provide a more uniform distribution of the deformation between the left and right sides of the prosthesis. When performing a retrievable Cement-retained, a better passive fit is achieved, which accords with the article published by Randi AP [10] where it was concluded that the retrievable Cement-retained have a better passive fit because the superstructure is cemented directly into titanium abutments, therefore there is no gap. Also, the study by da Rocha PV [14] showed that when performing a retrievable Cement-retained, the adhesion force between the abutment and the superstructure is not lost. Covey et al used zinc phosphate to unite this type of prosthesis, also concluding that using wide abutments does not improve retention against standard ones. McCartney JW [9] published the dental technique in which the superstructure is cemented to the gold cylinders, to achieve a passive fit. Cast prostheses generally present defects in the casting process, 8 however, in this 3D simulation the cast prosthesis has been created without any defect. If the 3D design had been created with defects the difference would have been much greater. Therefore, retrievable Cement-retained had better biomechanical performance; however, in vitro studies are recommended before this technique can be considered to be optimal.

\section{Conclusion}

Given the limitations of the present finite element study, the following conclusions can be made retrievable Cement-retained proved to transmit less stress to the implants, have a passive fit, and more efficient stress distribution, it is recommended to carry out clinical studies to potentiate that conclusion.

Conflict-of-interest notification. The authors declare no conflict of interest.

\section{References}

1. Astrand P, Ahlqvist J, Gunne J, Nilson H (2008) Implant treatment of patients with edentulous jaws: a 20-year follow-up. Clin Implant Dent Relat Res 10(4): 207-217.

2. Fischer K, Stenberg $\mathrm{T}$ (2012) Prospective 10-year cohort study based on a randomized controlled trial (RCT) on implantsupported full-arch maxillary prostheses. Part 1: sandblasted and acidetched implants and mucosal tissue. Clin Implant Dent Relat Res 14(6): 808-815.

3. Al-Fadda SA, Zarb GA, Finer Y (2007) A comparison of the accuracy of fit of 2 methods for fabricating implant-prosthodontic frameworks. Int J Prosthodont 20: 125-131.

4. Abduo J (2014) Fit of CAD/CAM implant frameworks: A comprehensive review. J Oral Implantol 40(6): 758-766.

5. Mazurat RD,Love WB (1993)Direct assembly of implant suprastructures. J Prosthet Dent 70(2): 172-175

6. Clelland NL, Van Putten MC (1997) Comparison of strains produced in a bone simulant between conventional cast and resin-luted implant frameworks. Int J Oral Maxillofac Implants 12(6): 793-799.

7. Katsoulis J, Takeichi T, Sol Gaviria A, Peter L, Katsoulis K (2017) Misfit of implant prostheses and its impact on clinical outcomes. Definition, assessment and a systematic review of the literature. Eur J Oral Implantol 10(Suppl 1): 121-138.

8. Carr AB, Stewart RB (1993) Full-arch implant framework casting accuracy: Preliminary in vitro observation for in vivo testing. J Prosthodont 2(1): 2-8.

9. McCartney JW, Doud R (1993) Passive adaptation of the prosthesisimplant interface by soldering gold cylinders to the framework casting. J Prosthet Dent 70(1): 17-20. 
10. Randi AP, Hsu AT, Verga A, Kim JJ (2001) Dimensional accuracy and retentive strength of a retrievable cement-retained implant-supported prosthesis. Int J Oral Maxillofac Implants 16(4): 547-556.

11. Aparicio C (1994) A new method to routinely achieve passive fit of ceramometal prostheses over Brånemark osseointegrated implants: A two-year report. Int J Periodontics Restorative Dent 14(5): 404-419.

12. Voitik AJ (1991) The Kulzer abutment luting; Kal technique. A direct assembly framework method for osseointegrated implant prostheses. Implant Soc 2(1): 11-14.
13. Rajan M, Gunaseelan R (2004) Fabrication of a cement- and screwretained implant prosthesis. J Prosthet Dent 92(6): 578-580.

14. da Rocha PV, Freitas MA, de Morais Alves (2013) Influence of screw access on the retention of cement-retained implant prostheses. J Prosthet Dent 109(4): 264-268.

15. Duyck J, Van Oosterwyck H, Vander Sloten J, De Cooman M, Puers R, et al. (2000) Magnitude and distribution of occlusal forces on oral implants supporting fixed prostheses: an in vivo study. Clin Oral Implants Res 11(5): 465-475.

For possible submissions Click below: 